\title{
Odontologia Defensiva e educação permanente: gestão de prontuários contribuindo na formação de cirurgiões-dentistas com responsabilidade profissional
}

Luiz Fernando Lolli*; Márcia Cristina da Silva**; Fernanda do Nascimento de Lemos Campos**; Amanda Penha Mathias***; Mariucha Ramella Marcon Nemer***

* Docente, Departamento de Odontologia, Universidade Estadual de Maringá, Coordenador do Curso de Odontologia da UEM

** Residente em Saúde Coletiva e da Família, Universidade Estadual de Maringá

*** Mestranda em Odontologia Integrada, Universidade Estadual de Maringá

Recebido em 30/08/2018. Aprovado em 26/12/2019.

\begin{abstract}
RESUMO
A documentação produzida na prática clínica odontológica deve ser valorizada pelos profissionais uma vez que se constitui em importante ferramenta clínica, administrativa e legal. Reclamações acerca da prestação de serviços odontológicos tem ocorrido não somente nas clínicas e consultórios privados, mas também no serviço público e nas instituições de ensino superior. O objetivo deste estudo foi relatar a experiência de gestão documental na Clínica de Odontologia da Universidade Estadual de Maringá (COD-UEM) realizada pelo Grupo de Estudos de Orientação Profissional e Odontologia Legal (GEOPOL). A gestão realizada é composta por vigilância de produção e atualização documental, gestão de retirada de documentos e adequação de arquivo. O GEOPOL é um projeto de ensino que tem trabalhado com a utilização de metodologias inovadoras e foco na Educação Permanente. O aprendizado ocorre com a vivência em cenário real de produção de documentos. Na vigilância de produção documental existe um checklist de atividades e as análises são registradas em um diário de ocorrências. A retirada de prontuários institucionais por pacientes ocorre por meio de protocolo de solicitação e os documentos entregues são preparados pelo GEOPOL. A organização do arquivo busca ajustar a demanda de atendimento à disposição logística de documentos. Observa-se que a gestão documental tem valorizado o trabalho realizado pela CODUEM, representando uma importante prestação de serviços para a comunidade interna e externa.

Descritores: Odontólogos. Responsabilidade Legal. Capacitação Profissional. Educação Continuada.
\end{abstract}




\section{INTRODUÇÃO}

Os documentos produzidos na prática odontológica são fundamentais em termos de Odontologia Defensiva por se constituírem provas técnicas das intervenções realizadas ou orientadas ${ }^{1}$. Os questionamentos relacionados à prestação de serviços odontológicos atualmente ocorrem em todos os locais, sejam consultórios, clínicas, unidades básicas de saúde e até mesmo instituições de ensino superior. A atenção odontológica para a população, seja em âmbito público ou privado, deve ocorrer sim com foco na qualidade dos serviços e na humanização do atendimento, mas também considerando o cuidado com os registros dos procedimentos. É preciso entender que a elaboração do prontuário na Odontologia é ato clínico e dever do cirurgião-dentista, previsto no Código de Ética Odontológica (CEO), que em seu capítulo VII esclarece sobre a elaboração e manutenção dos documentos odontológicos ${ }^{2}$.

A Odontologia Defensiva tem sido compreendida como um conjunto de medidas preventivas que tem por objetivo a proteção dos cirurgiões-dentistas contra riscos inerentes à própria profissão e que podem levar ao erro profissional, acarretando ações cíveis, criminais e/ou éticas ${ }^{3}$. Dentre as medidas de proteção profissional está a correta elaboração e manutenção de documentos odontológicos ${ }^{4-8}$.

$\mathrm{O}$ prontuário odontológico teve sua denominação sugerida em substituição à "ficha clínica" pela portaria do CFO 174/92 e deve ser compreendido como um conjunto de documentos que retrata a atenção prestada ao cliente, devendo ser minimamente constituído por um campo de identificação, Formulário de Anamnese, Ficha Clínica, Plano de Tratamento e Relatório de Atividades. O prontuário deve permitir ainda o arquivamento de $2^{\mathrm{a}}$ via de documentos emitidos (atestados, prescrições, encaminhamentos, solicitação de exames, orientações). Há de se ponderar ainda que o profissional pode agregar outros documentos importantes, como um contrato de prestação de serviços que detalhe melhor a relação jurídica profissional-paciente ${ }^{3}$. Com o intuito de auxiliar na correta elaboração do prontuário odontológico, os conselhos e instituições de ensino têm sugerido modelos que cumpram as exigências do CEO, bem como resoluções do Conselho Federal de Odontologia (CFO) pertinentes ao tema ${ }^{9-11}$.

Ao elaborar o prontuário odontológico, o profissional deve ter em mente que sua constituição precisa atender a 3 aspectos, sendo: clínico, administrativo e legal ${ }^{12}$. De fato, a produção, atualização e arquivamento adequado do prontuário odontológico representa proteção profissional, não somente por servir de meio de prova diante de questionamentos, mas também por representar anteparo para a tomada de decisões clínicas e administrativas, o que traz mais segurança de atuação e melhores resultados para os usuários e profissionais ${ }^{13}$.

O conceito de responsabilidade profissional tem sido trabalhado como o dever de reparar os danos provocados numa situação onde uma determinada pessoa sofre prejuízos como consequência de atos ilícitos praticados por outra ${ }^{7}$. $\mathrm{Na}$ realidade, é fácil imaginar que a prestação de serviços odontológicos ocorra com o maior zelo possível em relação ao paciente, sendo o profissional altamente diligente no sentido de fazer o bem e evitar o mal. Quando a relação profissional-paciente, por alguma razão, se enfraquece, surge o risco de reclamações judiciais, fato que evidencia o conceito de responsabilidade profissional. Neste momento a documentação odontológica assume vital importância como meios de $\operatorname{prova}^{14}$.

A Educação Permanente é um conceito que tem sido muito fortalecido no Brasil nas últimas duas décadas. Impulsionada por uma política nacional, ela parte do pressuposto de produzir saber ou conhecimento partindo de situações reais dos 
cenários de trabalho, considerando que o aprender e o ensinar são incorporados ao cotidiano das organizações e ao processo de trabalho, propondo que os processos de educação dos trabalhadores da saúde se façam a partir da problematização da própria prática ${ }^{15}$. Assim, tanto nas organizações de cuidado em saúde quanto no ambiente formador a Educação Permanente tem papel fundamental ${ }^{16}$.

A atividade desenvolvida pelo Grupo de Estudos de Orientação Profissional e Odontologia Legal (GEOPOL) oportuniza o aprendizado em um cenário real, atendendo ainda a uma necessidade de gestão documental do ambiente formador. É a integração entre gestão, produção de conhecimento com metodologia diferenciada e prestação de serviços à comunidade. Pela rotina de atuação estabelecida, os participantes vivenciam experiências de elaboração, ajuste, processamento, manutenção e arquivamento documental, fortalecendo seus domínios teóricos deontológicos com ênfase no prontuário e os aspectos clínicos, legais e administrativos.

O objetivo deste estudo foi descrever a metodologia de gestão de prontuários adotada na Clínica Odontológica da Universidade Estadual de Maringá (COD-UEM) frente aos aspectos éticos e legais da profissão com atuação na lógica da Educação Permanente.

\section{RELATO DE EXPERIÊNCIA}

Para a melhor compreensão do relato foi realizada a divisão temática em três tópicos.

\section{Vigilância de Produção e Atualização Documental:}

A ideia de gestão documental da COD-UEM teve seu ponto de partida no ano de 2013 com o surgimento do GEOPOL, grupo este cadastrado na UEM como projeto de ensino e no $\mathrm{CNPq}$ como grupo de pesquisa. Um levantamento de dados de prontuários ocorrido no mesmo ano 2013 demonstrou que, considerando os aspectos éticos e legais de Odontologia Defensiva, existiam pontos a serem melhorados.

Importante constar que na COD-UEM atuam acadêmicos de graduação, pós-graduação stricto sensu e lato sensu e os procedimentos vão desde aqueles da atenção básica até procedimentos especializados. Independentemente da complexidade, os atendimentos clínicos aos usuários do Sistema Único de Saúde são anotados em um prontuário único.

No ano 2017, o mesmo grupo iniciou um trabalho de gestão dos prontuários (figura 1) para atender as questões éticas e legais, conferindo melhor condição de responsabilidade profissional e também aos usuários da COD que passariam a ter a documentação produzida com mais critério. As atividades do GEOPOL são mediadas por um docente da área de Odontologia Legal com a participação de mestrandos, residentes e acadêmicos de graduação. Os prontuários são retirados em data e hora previamente definidas para serem avaliados, sem interferir com o andamento das atividades clínicas.

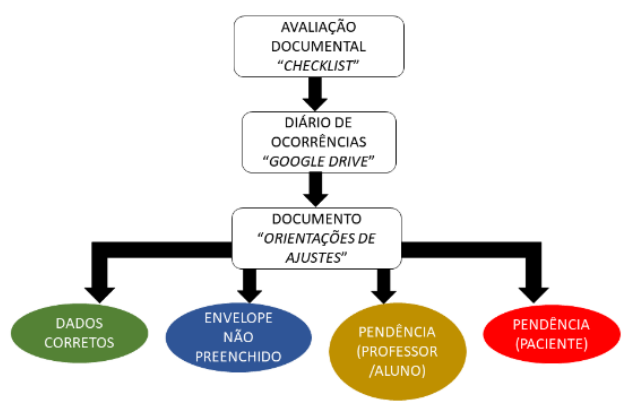

Figura 1. Fluxograma demonstrando as etapas da avaliação documental de prontuários da COD-UEM 
A avaliação documental consiste em verificar se o preenchimento está correto em sua plenitude, de acordo com orientações que os acadêmicos recebem em determinados momentos do curso, em disciplinas relacionadas. Para a avaliação dos documentos, o GEOPOL dispõe de um checklist (quadro I) onde constam as variáveis que devem ser consideradas. Após a avaliação, é preenchido um diário de ocorrências na nuvem (Drive do Google), para permitir que mais de uma análise documental possa ser realizada em paralelo ou que pessoas autorizadas de diferentes locais possam acessar em tempo real o que está sendo produzido (figura 2).

Quadro 1. Checklist de verificação do preenchimento documental de prontuários da COD-UEM

\begin{tabular}{|l|l|}
\hline TÓPICO & \multicolumn{1}{|c|}{ VERIFICAR } \\
\hline Termos & Verificar se tem termo de ciência ou de alta com assinatura de paciente na 2a via \\
\hline Identificação & $\begin{array}{l}\text { Verificar se todos os campos estão preenchidos; verificar se tem documento do } \\
\text { paciente; }\end{array}$ \\
\hline Anamnese & $\begin{array}{l}\text { Verificar se todos os campos estão preenchidos. Se necessário, solicitar correção } \\
\text { para inserir a palavra "nega"; verificar se tem assinatura do paciente ou } \\
\text { responsável. }\end{array}$ \\
\hline Exame físico & $\begin{array}{l}\text { Verificar se tem registros de exame extrabucal; verificar se tem registros de exame } \\
\text { intrabucal. }\end{array}$ \\
\hline $\begin{array}{l}\text { Plano de tratamento } \\
\text { atividades }\end{array}$ & $\begin{array}{l}\text { Verificar se estão preenchidas opções de tratamento, ao menos 2; verificar se tem } \\
\text { assinalada a opção escolhida; verificar se tem assinatura do paciente; verificar se } \\
\text { tem assinatura do estudante; verificar se tem assinatura do professor }\end{array}$ \\
\hline Documentos emitidos & $\begin{array}{l}\text { Verificar se tem registro de prescrição - confrontar com segunda via assinada pelo } \\
\text { paciente; verificar se tem assinatura de paciente; verificar se tem assinatura de } \\
\text { docente; verificar se tem assinatura do estudante. }\end{array}$ \\
$\begin{array}{l}\text { Verificar se tem segunda via de documentos emitidos (atestado, prescrição, } \\
\text { encaminhamento, solicitação de avaliação médica, etc) sem assinatura de } \\
\text { paciente. }\end{array}$ \\
\hline Envelope & $\begin{array}{l}\text { Verificar se é o envelope correto e se está preenchido adequadamente, indicando } \\
\text { a situação do paciente na COD-UEM. }\end{array}$ \\
\hline
\end{tabular}

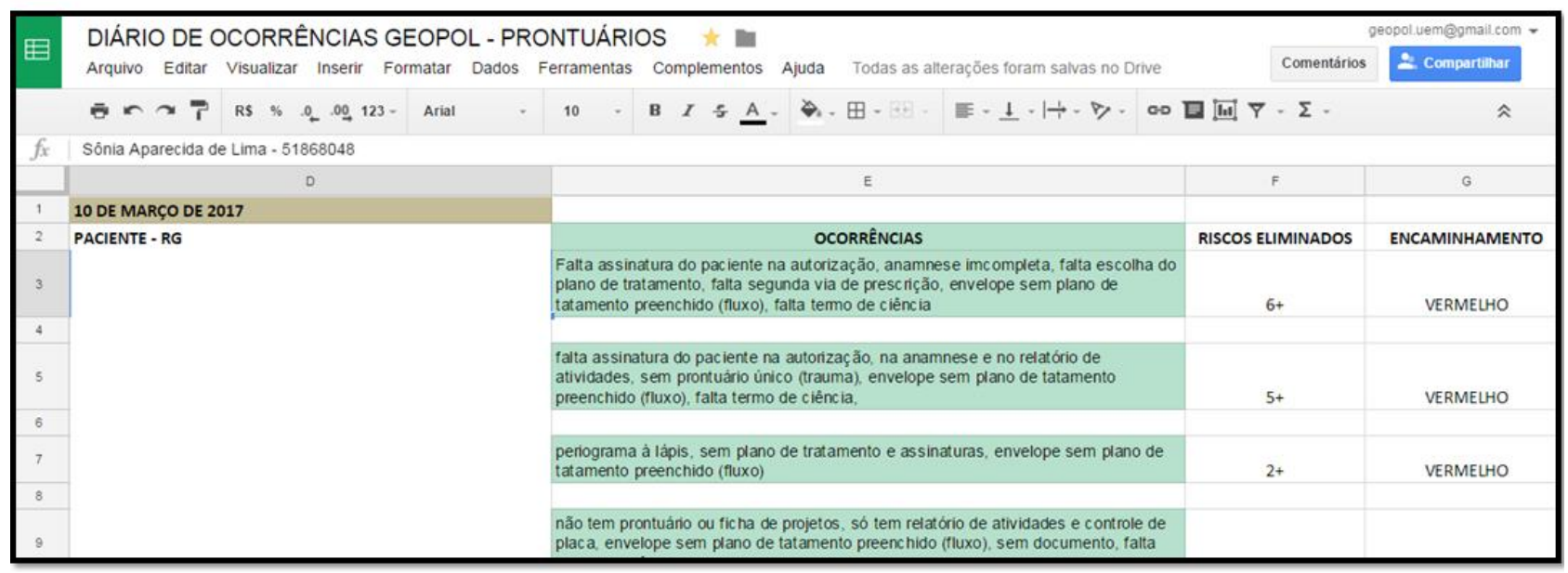

Figura 2. Diário de ocorrências da verificação de preenchimento dos prontuários odontológicos da CODUEM 
Um documento contendo orientações de ajustes é formulado e segue afixado ao prontuário quando do retorno do mesmo para as dependências do arquivo institucional. Assim, quando o acadêmico retira o prontuário para o atendimento do usuário se depara com a carta de recomendações. É responsabilidade dos acadêmicos providenciar os ajustes, havendo o risco de receber sanções disciplinares em caso de não cumprimento. Mesmo realizando o solicitado, também é pedido que não seja destacada a carta afixada, para permitir posterior conferência.

O prontuário único e integrado utilizado pela COD-UEM possui um envelope (figura 3 ) onde são afixadas fitas de cores diversas, no sentido longitudinal, segundo a classificação de risco: fita vermelha, quando faltam dados, documento(s) ou assinatura(s) do(a) paciente; fita amarela, quando existem pendências de professores ou estudantes; fita azul, quando falta apenas o preenchimento do envelope do prontuário; e fita verde, quando todos os dados estão preenchidos corretamente.

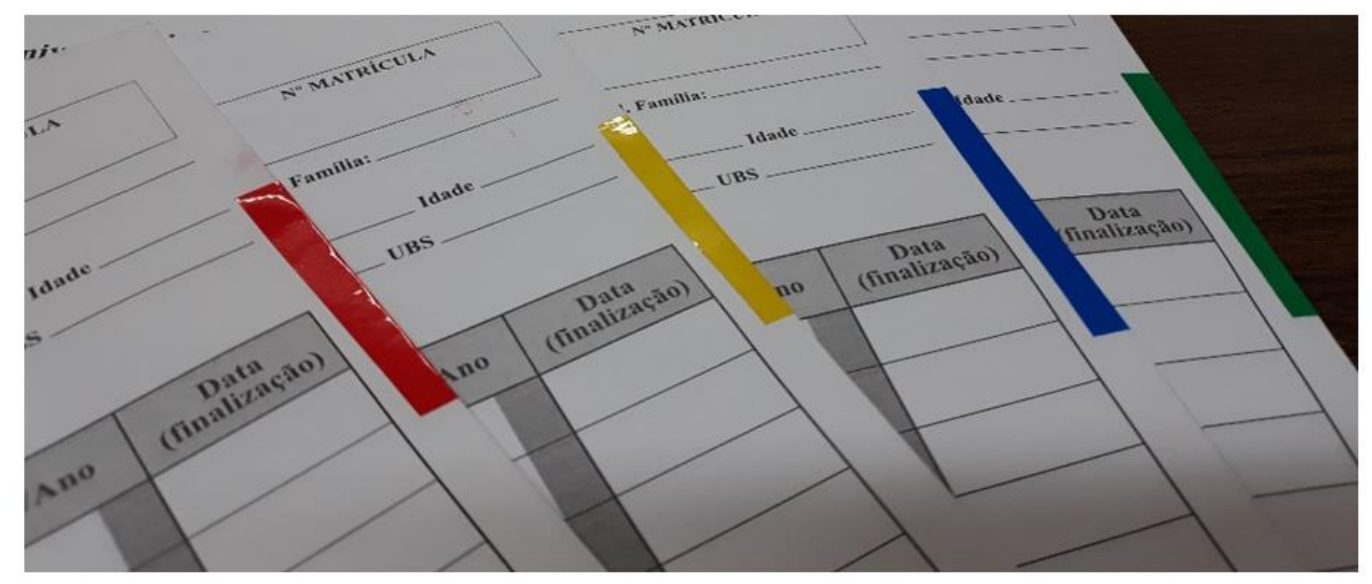

Figura 3. Envelope do prontuário único da COD-UEM com fitas correspondentes à situação do seu preenchimento

Esta atividade foi realizada por 15 meses até o presente momento. Uma breve avaliação demonstrou que a mesma tem sido bem aceita por docentes e discentes do Curso de Odontologia. Há relatos de que estudantes têm procurado fazer ajustes em determinados prontuários antes que estes sejam retirados pelo GEOPOL, que houve mudança de comportamento de discentes em relação à produção documental e questionamentos diversos para a melhoria da documentação. Além disto, houve significativa redução da perda de informações, de remarcações ou realização de procedimentos desnecessários. Tudo isto tem contribuído para a otimização de recursos públicos e o bom funcionamento do sistema como um todo.
Há de se ponderar obviamente quanto à proteção legal que esta atividade proporciona aos docentes, principais responsáveis pelos procedimentos realizados em pacientes no ambiente formador ${ }^{17}$.

A gestão documental tem sido interpretada como uma atividade que aprimora, ao mesmo tempo, aspectos de Odontologia Defensiva e ações de Educação Permanente. O primeiro aspecto é contemplado pela adoção de medidas preventivas na produção de registros frente aos ditames éticos e legais de preenchimento documental. O segundo aspecto é contemplado porque a atividade representa uma forma de aprendizado relacionado à prática desenvolvida sobre uma ação rotineira, 
indissociável da ação clínica odontológica. Em outras palavras, é um aprendizado advindo do toque na realidade dos fatos. É aprender com ações concretas.

O aprendizado efetivo ocorre quando o aprendiz vê, toca, percebe e atribui significado, quando lhe desperta os sentidos ${ }^{18}$ e é justamente nesta vertente de exposição de realidade que o GEOPOL tem trabalhado.

A atividade desenvolvida pelo GEOPOL, além de promover o aprendizado no cenário real de produção e vigilância documental, oferece um feedback aos estudantes sobre os pontos a serem melhorados na elaboração dos prontuários clínicos, indica ações a serem tomadas, e também aponta os pontos positivos encontrados. Outros estudos têm apontado o feedback como instrumento no processo aprendizagem ${ }^{19,20}$, e revelam que esta prática tem sido valorizada pelos discentes, além de promover melhor desempenho na educação universitária ${ }^{19}$.

As metodologias ativas de ensinoaprendizagem têm sido implementadas na UEM desde 2006, com o uso da problematização, porém poucos trabalhos têm sido publicados a respeito da integração serviço-ensino na Odontologia. Ainda assim, tal recurso tem se mostrado alternativa didático pedagógica viável, com aceitação no meio acadêmico, tanto de graduandos, como pósgraduandos e docentes ${ }^{21}$.

Dessa forma, a proposta do sistema de gestão aplicado segue recomendações das Diretrizes Curriculares Nacionais (DCN) ${ }^{22}$, que em seu artigo 13, inciso III, orienta a utilização de metodologias ativas de ensino/aprendizagem que permitam a participação ativa dos estudantes.

\section{Gestão de Retirada Documental}

Um fato que tem se tornado comum na COD-UEM, talvez comum em todos os locais de produção de cuidados odontológicos, é a solicitação, por parte dos usuários, de retirada de prontuários clínicos. Os prontuários são compostos pelos arquivos produzidos pelo preenchimento documental e muitas vezes incluem a documentação complementar de diagnóstico (radiografias periapicais, panorâmicas, telerradiografias, modelos e outros). As solicitações de retirada de documentos ocorrem por inúmeros motivos, e podem estar associadas à ilustração, judicial ou ética, de reclamações acerca do atendimento prestado ou ao que se esperava do atendimento.

Em março de 2017 o GEOPOL se dispôs a realizar a gestão de retirada documental, considerando também os aspectos éticos e legais e a Odontologia Defensiva. Assim, a retirada de documentos foi formalizada e todos os cuidados de atenção ao usuário e proteção profissional e institucional são tomados.

Para solicitar retirada do prontuário, o usuário maior de idade ou, no caso de menores ou incapazes, o responsável legal até $2^{\circ}$ grau de parentesco (ou pessoa que tenha a guarda judicial do(a) incapaz), faz a solicitação formal, preenchendo formulário apropriado no protocolo do Hospital Universitário da UEM. O protocolo é encaminhado para a secretaria da COD-UEM. O usuário tem ciência do prazo de sete dias úteis para a preparação da documentação solicitada e também de que após este período deverá retirar o solicitado nas dependências da COD-UEM.

Ao receber o protocolo de solicitação, a secretaria da COD encaminha o mesmo ao mediador do GEOPOL para providências. É feita a busca do prontuário no arquivo institucional. Para o processamento do prontuário, são levados em consideração bases legislativas e deontológicas. $\mathrm{O}$ parâmetro ético é o CEO (Resolução CFO $118 / 2012)^{23}$. Em termos legislativos são parâmetros a Constituição Federal (Brasil 1988) ${ }^{24}$, o Código Civil (Brasil, 2002) ${ }^{25}$ e o Código de Defesa do Consumidor (Brasil, 1990) ${ }^{26}$.

Quando o prontuário solicitado não contém 
exames complementares, ocorre apenas a avaliação do mesmo em relação ao conteúdo. Uma cópia é preparada para ser entregue ao solicitante. Quando o prontuário contém documentação complementar de diagnóstico, além da avaliação de preenchimento é preparada cópia da documentação complementar. Entretanto, se o paciente tiver realizado a documentação externamente e pagado por ela, leva os originais e a cópia fica na COD. Caso os exames tenham sido realizados na UEM, o paciente leva a cópia e a COD fica com os originais. No caso dos modelos, os mesmos são fotografados, eventualmente escaneados em 3D ou ainda, quando possível, duplicados para o arquivo institucional.

A entrega do material solicitado é realizada em data e hora previamente marcada, normalmente na sexta-feira e na presença do mediador do GEOPOL. O atendimento personalizado tem também a finalidade de conhecer melhor o paciente, saber de suas expectativas e do animus operandi acerca da documentação solicitada. Também é aproveitado o momento para a transmissão de orientações e para a solução de dúvidas dos usuários.

\section{Adequação do Setor de Acolhimento e Arquivo}

A readequação da gestão documental tem sido acompanhada por ajustes nos setores de acolhimento e arquivo. Até o final de 2016 o prontuário único e integrado era utilizado somente para os atendimentos na COD-UEM realizados pela graduação e pós-graduação stricto sensu (mestrado e doutorado). Entretanto, os atendimentos de projetos (pesquisa e extensão) e cursos de pós-graduação lato sensu (especialização e residência) eram realizados em outros formulários. Também o arquivamento destes outros formulários vinha ocorrendo em locais distintos do setor de acolhimento. Não que tais formas de organização fossem incorretas, mas apenas dificultavam a gestão integrada dos documentos produzidos.

No ano 2017 a então gestão da COD, do Departamento de Odontologia (DOD) e do Conselho Acadêmico do Curso de Odontologia, apoiado pelo GEOPOL, fez a proposição de se adotar o prontuário único em todas as atividades de atendimento ao usuário e também sugeriu fazer o arquivo em um só local, sendo, no caso, o setor de acolhimento. A ideia foi unificar o local de manutenção de registros de todos os usuários atendidos na COD, independentemente se o atendimento ocorra via projetos, graduação ou pósgraduação.

Os projetos que possuem formulários específicos, como por exemplo para lesões bucais, trauma, projeto bebê, podem se utilizar destes formulários, mas integrando-os ao prontuário único e não em substituição a ele. Assim, o prontuário único ganhou o status de obrigatoriedade para todos, e os documentos complementares devem ser acoplados a este, sem substituí-lo.

Com as mudanças propostas havia também a necessidade de se readequar o espaço físico do setor de acolhimento, o que foi realizado em espaço complementar, intitulado arquivo 2. Considerando o exposto, a estrutura organizacional do setor de acolhimento tem sido ajustada para ter:

- arquivo de usuários em atendimento; que fica no próprio setor de acolhimento, representado pelos prontuários de pacientes que estão em processo de atendimento na COD, com retornos agendados para projetos, cursos de pós-graduação ou graduação; - arquivo 1; com localização estratégica (sala localizada em frente ao setor de acolhimento), é um arquivo que abriga prontuários de pacientes que tiveram seus tratamentos finalizados há até 5 anos; e - arquivo 2; com localização mais afastada, em sala apropriada para permitir pesquisas documentais, é espaço que abriga 
prontuários de pacientes cujos tratamentos foram finalizados há mais de 5 anos. $\mathrm{Na}$ reestruturação proposta, será neste ambiente que se iniciará o processo de digitalização de prontuários antigos da COD-UEM para a constituição de um acervo digital.

\section{CONSIDERAÇÕES FINAIS}

A metodologia de gestão documental em andamento tem trazido benefícios formativos, tanto para os estudantes participantes do projeto, quanto para os demais envolvidos nas atividades clínicas da COD-UEM, fortalecidos por uma metodologia de ensino-aprendizagem prática num cenário real. O prontuário melhor estruturado favorece os aspectos clínicos, administrativos e legais relacionados à documentação odontológica.

A organização documental tem representado relevante benefício social, uma vez que as ações desenvolvidas dispensam maior atenção aos usuários, cuidando da adequada evolução clínica destes na COD-UEM, prevenindo a perda de vínculo ou de informações, evitando assim intervenções repetidas ou desnecessárias.

A gestão de documentos aliada a questões legais confere proteção profissional, especialmente aos docentes, responsáveis por procedimentos clínicos realizados pelos estudantes, considerando que os elementos probatórios ficam melhor estruturados, de acordo com os preceitos éticos e legais de Odontologia Defensiva. Além do exposto, a documentação bem elaborada, preparada e arquivada tem favorecido os aspectos logísticos de organização.

Há de se considerar que, no início dos trabalhos, houve dificuldade na compreensão do protocolo de classificação dos prontuários e a associação disso com questões clínicas, administrativas e legais por parte dos discentes e docentes. Com o tempo, as dificuldades foram sendo sanadas com ajustes na metodologia, maior exposição destas questões em reunião de
Departamento e nas clínicas da instituição para esclarecimentos.

Recomenda-se a análise permanente do método e dos dados coletados no sentido de se monitorar a eficácia do proposto, que envolve a integração entre gestão com produção do conhecimento e prestação de serviços à comunidade.

\section{ABSTRACT \\ Defensive Dentistry and permanent education: management of dental records contributing to the formation of dentists with professional responsibility}

Dental records produced in dental practice should be valued by practitioners once it constitutes an important clinical, administrative and legal tool. Patient complains about the provision of dental services have occurred not only in private clinics, but also in public service and dental colleges. The object of this study was to report the experience of documentary management at the Dentistry Clinic of the Universidade Estadual de Maringá (COD-UEM), conducted by the Legal Dentistry and Professional Orientation Study Group (GEOPOL). The management tasks comprehend documentary production and update, administration of documents withdrawal by patients and archives adequation. GEOPOL is a teaching Project that uses innovative methodologies and focuses on Permanent Education. Learning takes place with experience in real scenario of document production. In documentary production monitoring there is a checklist of activities, where the evaluated data is recorded in a journal of occurrences. The withdrawal of institutional records by patients occurs through a protocol request, in which GEOPOL prepares the documents to be delivered. The archive organization aims to adjust the demand for dental care and strategic location of dental records. It is observed that the document management has valued the work done by COD-UEM, representing an important service provided for the internal and external community. 
Descriptors: Dentists. Legal Liability. Professional Training. Education, Continuing.

\section{REFERÊNCIAS}

1. Amorim HPL, Marmol SLP, Cerqueria SNN, Silva MLCA, Silva UA. A importância do preenchimento adequado dos prontuários para evitar processos em Odontologia. Arq

Odontol. 2016;52(1):32-7.

2. Conselho Federal de Odontologia. Resolução CFO 118 de 11 de maio de 2012. Código de ética odontológica.

3. Onesti A. Odontologia defensiva e prática clínica de baixo risco [tese]. São Paulo: Faculdade de Odontologia; 2010.

4. Garbin CAS, Garbin AJI, Lelis RT. Verificação das atitudes de cirurgiõesdentistas quanto à documentação de seus pacientes. Rev Assoc Paul Cir Dent. 2006;60(6):442-5.

5. Paranhos LR, Salazar M, Ramos AL, Siqueira DF. Orientações legais aos cirurgiões-dentistas. Rev Odonto. 2007; 15(30):55-62.

6. Paranhos LR, Caldas JCF, Iwashia AR, Scanavini MA, Paschini RC. A importância do prontuário odontológico nas perícias de identificação humana. RFO UPF. 2009;14(1):14-7.

7. Cruz SF, Mathias AP, Viana BAS, Silva NS, Alves MD, Lolli LF. Esclarecendo a responsabilidade civil do cirurgiãodentista. Acta JUS. 2018;11(1):5-10.

8. Lolli LF, Lolli MCGS, Marson FC, Silva COE, Moreira MA, Silva RHA. Responsabilidade Criminal do CirurgiãoDentista. Acta JUS. 2013;1:17-23.

9. Brasil. Conselho Federal de Odontologia. Prontuário odontológico: uma orientação para o cumprimento da exigência contida no inciso VIII do art. $5^{\circ}$ do Código de Ética
Odontológica. CFO. Rio de Janeiro. 2004.

10. Brasil. CFO. Resolução CFO 91/2009. Aprova as normas técnicas concernentes à digitalização, uso dos sistemas informatizados para a guarda e manuseio dos documentos dos prontuários dos pacientes, quanto aos Requisitos de Segurança em Documentos Eletrônicos em Saúde. Rio de Janeiro; 2009.

11. Amorim HP, Marmol SLP, Cerqueria SNN, Silva MLCA, Silva UA. A importância do preenchimento adequado dos prontuários para evitar processos em Odontologia. Arq Odontol. 2016;52(1): 32-7.

12. Ramos DLP, Calvielli ITP. Sugestão de composição de inventário de saúde do paciente. Rev Odonto. 1991;1:42-5.

13. Saraiva AS. A importância do prontuário odontológico - com ênfase nos documentos digitais. Rev Bras Odontol. 2011;68(2):157-60.

14. Zanin AA, Strapassom RAP, Melani RFH. Levantamento jurisprudencial: provas em processo de responsabilidade civil odontológica. Rev Assoc Paul Cir Dent. 2015;69(2):120-7.

15. Almeida JRS, Bizerril DO; Saldanha KGH, Almeida MEL. Educação Permanente em Saúde: uma estratégia para refletir sobre o processo de trabalho. Rev ABENO. 2016;16(2):7-15.

16. Farias CML, Cardoso BDF, Santos Neto ET, Carvalho RB, Curtis D. Feedback no processo de aprendizagem: percepção dos estudantes de Odontologia em uma universidade brasileira. Rev ABENO. 2015;15(3):35-42.

17. Nogueira TH, Campos e Santos C, Petroski TCA, Galvao APB, Neto Filho MA, Lolli MCGS, et al. Responsabilidade Profissional do Cirurgião Dentista 
Docente. Braz J Surg Clin Res. 2014;8:8491.

18. Paiva MRF, Parente JRF, Brandão IR, Queiroz AHB. Metodologias ativas de ensino aprendizagem: revisão integrativa. Sanare (sobral, online). 2016;15(2):14553.

19. Farias CML; Cardoso BDF; Neto ETS; Carvalho RB; Curtis D. Feedback no processo de aprendizagem: percepção dos estudantes de Odontologia em uma universidade brasileira. Rev ABENO. 2015;15(3):35-42.

20. Zeferino AMB, Domingues RCL, Amaral E. Feedback como estratégia de aprendizado no ensino médico. Rev Bras Educ Med 2007; 31(2):176-9.

21. Carvalho WM, Cawahis PT, Scheibel PC, Botelho JN, Terada RSS, Rocha NB, Lolli LF, Fujimaki M. Aceitação da utilização de metodologias ativas nos estágios no SUS por discentes da graduação e pósgraduação em Odontologia. Rev ABENO. 2016;16 (1):88-98.

22. Almeida M (org). Diretrizes Curriculares Nacionais para os Cursos Universitários da
Área de Saúde. $2^{a}$ ed. Londrina: Ed. Rede Unida; 2005.

23. Brasil. Conselho Federal de Odontologia. Revoga o Código de Ética Odontológica aprovado pela Resolução CFO-42/2003 e aprova outro em substituição. Resolução $n$. 118, de 11 de maio de 2012. [Acesso em 07 junho 2016]. Disponível em: http://cfo.org.br/wpcontent/uploads/2009/09/codigo_etica.pdf.

24. Brasil. Constituição (1988). Constituição da República Federativa do Brasil. Brasília, DF: Senado Federal; 1988.

25. Brasil. Lei n. 10.406, 10 de janeiro de 2002. Institui o Código Civil. Diário Oficial da União. 11 jan 2002.

26. Brasil. Lei $\mathrm{n}^{\circ}$. 8.078, de 11 de setembro de 1990. Código de Defesa do Consumidor. Diário Oficial da União. 12 set 1990.

\section{Correspondência para:}

Luiz Fernando Lolli

e-mail: profdrluizfernando@gmail.com

Av. Mandacaru, 1550 - Centro

87080-000 Maringá/PR 